Caries Res. 1985;19:I-VII

\title{
Contents, Vol. 19, 1985
}

\section{No. 1 Basic Sciences}

Chemical and Histological Changes during Development of Artificial Caries

Featherstone, J.D.B.; Holmen, L.; Thylstrup, A.; Fredebo, L.; Shariati, M 1

A Scanning Electron Microscopic Study of Surface Changes during Development of Artifi cial Caries

Holmen, L.; Thylstrup, A.; Featherstone, J.D.B.; Fredebo, L.; Shariati, M 11

Kinetic and Thermodynamic Aspects of Enamel Demineralization

Margolis, H.C.; Moreno, E.C 22

Development of Carious-Like Lesions in Partially Saturated Lactate Buffers

Margolis, H.C.; Murphy, B.J.; Moreno, E.C 36

Long-Term Retention and Effectiveness of APF and Neutral KF Fluoridation Agents on

Sound and Etched Bovine Enamel

Valk, J.W.P.; Duijsters, P.P.E.; Cate, J.M. ten; Davidson, C.L

Transport and Phosphorylation of Xylitol by a Fructose Phosphotransferase System in

Streptococcus mutans

Trahan, L.; Bareil, M.; Gauthier, L.; Vadeboncoeur, C

Additive Inhibitory Effects of Combinations of Fluoride and Chlorhexidine on Acid Produc tion by Streptococcus mutans and Streptococcus sanguis

McDermid, A.S.; Marsh, P.D.; Keevil, C.W.; Ellwood, D.C 64

Effects of Ionic Organic Materials on Enamel Demineralization (Short Communication)

Tung, M.S.; Brown, W.E 72

Clinical Science

Changes in Caries Prevalence among Adolescents in Budapest, Hungary, from 1975 to 1982

Bánóczy, J.; Boross, É.; Nemes, J.; Ember, G.; Pados, R 76

An Empirically Based System to Estimate the Effectiveness of Caries-Preventive Agents.

A Comparison of the Effectiveness Estimates of APF Gels and Solutions, and Fluoride

Varnishes

Clark, D.C; Hanley, J.A.; Weinstein, P.L.; Stamm, J.W

Announcement 96

No. 2 Basic Sciences

Micro-Sampling by Abrasion

Weatherell, J.A.; Robinson, C; Strong, M.; Nakagaki, H

Enamel Fluoride Profile Construction from Biopsy Data

Chow, L.C.; Beaudreau, G.M.; Brown, W.E. 103

Raman Spectra of Phosphate and Monofluorophosphate Ions in Several Dentally-Relevant Materials

Nelson, D.G.A.; Williamson, B.E 113

Effect of Soluble Calcium on Fluoride Uptake by Artificial Caries Lesions in vivo

Mellberg, J.R.; Chomicki, W.G 122 
IV Contents

Remineralization in vivo of Artificial Caries Lesions by a Monofluorophosphate Denti frice

Mellberg, J.R.; Chomicki, W.G.; Mallon, D.E.; Castrovince, L.A 126

Intraoral Demineralization and Maltose Clearance from Wheat Starch

Brudevold, F.; Goulet, D.; Tehrani, A.; Attarzadeh, F.; Houte, J. van 136

Animal Studies

Single Fluoride Doses and Enamel Fluorosis in the Rat

Angmar-Månsson, B.; Whitford, G.M 145

Abstracts

Abstracts of Papers Presented at the 31 st ORCA Congress

July 4-7, 1984, Nordwijkerhout, The Netherlands 153

No. 3 Basic Sciences

Stability of Selected Plaque Species and Their Relationship to Caries in a Child Population over 2 Years

Burt, B.A.; Loesche, W.J.; Eklund, S.A 193

ATP Content and Viability of Human Dental Plaque during Prolonged Starvation

Greger, J.E.G.; Eisenberg, A.D 201

Effect of Sucrose as a Gustatory Stimulus on the Flow Rates of Parotid and Whole Saliva

Lagerlöf, F.; Dawes, C 206

Rehardening Properties of Mucin- or CMC-Containing Saliva Substitutes on Softened

Human Enamel. Effects of Sorbitol, Xylitol and Increasing Viscosity

Vissink, A.; 's-Gravenmade, E.J.; Gelhard, T.B.F.M.; Panders, A.K.; Franken, M.H. . 212

Chemical and Physical Evaluation of Dialyzed-Reconstituted Acidified Gelatin Surface

Lesions of Human Enamel

Feagin, F.F.; Clarkson, B.H.; Wefel, J.S 219

Self-Gelling Liquid Composition for Topical Application of Medications

Gron, P.; Caslavska, V 228

Influence of Tooth Paste Particle Size and Tooth Brush Stiffness on Dentine Abrasion in

vitro

De Boer, P.; Duinkerke, A.S.H.; Arends, J 232

Fluoride Uptake by Dentin Surfaces following Topical Application of TiF4, NaF and Fluoride Varnishes in vivo

Tveit, A.B.; Tötdal, B.; Klinge, B.; Nilvéus, R.; Selvig, K.A

An Evaluation of Three Procedures for Fluoride Analysis

Retief, D.H.; Summerlin, D.-J.; Harris, B.E.; Bradley, E.L 248

Intraoral Uptake of Fluoride by Presoftened Enamel following Systemic Administration and Fluoride Mouthrinsing

Zimmermann, M.B.; Koulourides, T.; Muhammad, N.A.; Corpron, R.E.; Higuchi, W.I.;

Kowalski, C.J 255

Fluoride Concentration in Deciduous Enamel in High- and Low-Fluoride Areas (Short

Communication)

Iijima, Y.; Katayama, T

262

Effect of Alpha-Amylase Inhibitors and Other Compounds on Glucosyltransferase Activity

(Short Communication)

Takehara, T.; Newbrun, E.; Hoover, C.I 266 
Contents V

Clinical Science

A 3-Year Longitudinal Caries Study of Permanent Tooth Surfaces at Risk in Finnish School

Children

Nordblad, A.; Larmas, M 271

Caries Prevalence and Dental Fluorosis in German Children in Areas with Different Con centrations of Fluoride in Drinking Water Supplies

Hellwig, E.; Klimek, J278

The Relationship between Anticaries Activity of Monofluorophosphate Dentifrices and

Their Performances in Laboratory Tests

Duke, S.A.; Forward, G.C 284

No. 4 Basic Sciences

The Microflora Associated with Developing Lesions of Nursing Caries

Milnes, A.R.; Bowden, G.H.W 289

The Microflora Associated with the Progression of Incipient Carious Lesions in Teeth of

Children Living in a Water-Fluoridated Area

Boyar, R.M.; Bowden, G.H 298

Adenosine 5'-Triphosphate Content of Streptococcus mutans GS-5 during Fluoride-Mediated

Death at Low $\mathrm{pH}$

Greger, J.E.G.; Izaguirre-Fernández, E.J.; Eisenberg, A.D 307

Adenosine 5'-Triphosphate Content of Streptococcus mutans GS-5 during Starvation in a

Buffered Salt Medium

Greger, J.E.G.; Eisenberg, A.D 314

Determination of Salivary Streptococcus mutans Level in a Stable Sucrose-Sulphasomidine-

Containing Broth

Kalfas, S.; Edwardsson, S.; Birkhed, D 320

Effect of Human Milk on Plaque pH in situ and Enamel Dissolution in vitro Compared with

Bovine Milk, Lactose, and Sucrose

Rugg-Gunn, A.J.; Roberts, G.J.; Wright, W.G

Enhancement of (Salivary) Remineralization by 'Dipping' Solutions

Cate, J.M. ten; Shariati, M.; Featherstone, J.D.B 335

F" Uptake Inhibition by Excess Phosphate during Fluoridated Apatite Formation

Okazaki, M.; Takahashi, J.; Kimura, H 342

A Polarized Light Microscopic Study of Progressive Stages of Enamel Caries in vivo

Holmen, L.; Thylstrup, A.; Øgaard, B.; Kragh, F 348

A Scanning Electron Microscopic Study of Progressive Stages of Enamel Caries in vivo

Holmen, L.; Thylstrup, A.; Øgaard, B.; Kragh, F 355

Animal Studies

Effect of Calcium Lactate and Calcium Lactophosphate on Caries Activity in Programme-

Fed Rats (Short Communication)

Hoeven, J.S. van der 368

Clinical Science

Posttreatment Benefits from Participation in a School-Based Fluoride Mouthrinsing Pro gram: Results after up to 7 Years of Rinsing

Leske, G.S.; Ripa, L.W.; Sposato, A.; Rebich, T., Jr 371

Contents 
The Use of Fibre-Optic Transillumination in the Diagnosis of Posterior Approximal Caries in Clinical Trials (with 1 colour plate)

Mitropoulos, CM 379

Basic Sciences

The Relationship between Dental Caries and Tooth Enamel Fluoride

Mellberg, J.R.; Ripa, L.W.; Leske, G.S.; Sanchez, M.; Polanski, R 385

Posteruptive Maturation of Tooth Enamel Studied with the Electron Microprobe

Driessens, F.C.M.; Heijligers, H.J.M.; Borggreven, J.M.P.M.; Wöltgens, J.H.M 390

Enamel Lesion Formation with and without 0.12 ppm F in Solution

Borsboom, P.C.F.; Mei, H.C. v.d.; Arends, J 396

Scanning X-Ray Microradiographic Study of the Formation of Caries-Like Lesions in Synthetic Apatite Aggregates

Anderson, P.; Elliott, J.C 403

In vivo Effect of a Fluoridating Varnish with Various Fluoride Contents on Human

Enamel

Bruyn, H. de; Hummel, M.; Arends, J 407

Effect of Salivary Lysozyme on Glucose Incorporation and Acid Production in Streptococcus mutans

Twetman, S.; Lindqvist, L 414

Effect of a School-Based Plaque Control Programme on the Microbiology of Dental

Plaque

Ashley, F.P.; Wilson, R.F.; Woods, A.P.M 422

The Effect of Low Doses of Fluoride on the Content of Cyclic AMP and Amylase in Human Parotid Saliva

Mörnstad, H.; Dijken, J. van 433

Maltotriitol Inhibition of Maltose Metabolism in Streptococcus mutans via Maltose Transport, Amylomaltase and Phospho- $\alpha$-Glucosidase Activities

Würsch, P.; Koellreutter, B 439

Time Dependence of F Uptake in Demineralized Enamel from 1,000-ppm Fluoride NaF and Na2FP03 Solutions. A Secondary Ion Mass Spectrometric Study (Short Communication) Arends, J.; Schuthof, J.; Petersson, L.; Lodding, A 450

Effect of Fluoride, Lithium or Strontium on Acid Production by Pelleted Human Dental

Plaque (Short Communication)

Eisenberg, A.D.; Wegman, M.R.; Oldershaw, M.D.; Curzon, M.EJ 454

Animal Studies

Effect of Two Recently Developed Antiseptics on Dental Plaque and Caries in Rats

Shern, R.J.; Monell-Torrens, E.; Kingman, A 458

Comparison of the Cariostatic Effect of Topically and Systematically Administered Con-trolled-

Release Fluoride in the Rat Mirth, D.B.; Adderly, D.D.; Monell-Torrens, E.; Amsbaugh, S.M.;

Li, S.-M.; Bowen, W.H. 466

Clinical Science

Plasma Fluoride Levels in 9 Children with Acute Lymphatic Leukaemia Using Daily Self-

Applied Fluoride Gels

Purdell-Lewis, D.J.; Dijk, H.A. van; Heeres, G.J.; Flissebaalje, T.D.; Groeneveld, A.;

Booji, M 475

Contents VII 
No. 6 Basic Sciences

Initiation and Progression of Caries-Like Lesions of Enamel: Effect of Periodic Treatment with Synthetic Saliva and Sodium Fluoride

Hicks, M.J.; Flaitz, CM.; Silverstone, L.M 481

Lesion Formation and Lesion Remineralization in Enamel under Constant Composition

Conditions. A New Technique with Applications

Buskes, J.A.K.M.; Christoffersen, J.; Arends, J

490

Selection of a Micromethod and Its Use in the Estimation of Salivary Streptococcus mutans and Lactobacillus Counts in Relation to Dental Caries in Tanzanian Children

Matee, M.I.; Mikx, F.H.M.; Frencken, J.E.F.N.; Train, G.J.; Ruiken, H.M.H.M. ... 497 Effect of

Saliva Substitutes upon Binding of Selected Oral Bacteria to Hydroxyapatite (Short

Communication)

Wolinsky, L.E.; Seto, B.; Cerveny, R507

Measurements of Alkaline Phosphatase Activity in Fetal Bovine Enamel (Short Communication)

Sailing, E.; Kirkeby, S.; Moe, D 512

Animal Studies

A Simple Model for Root Caries and Alveolar Bone Recession in Rats (Short Communi cation)

Guggenheim, B.; Lutz, F 516

Clinical Science

Development of Dental Fluorosis according to Age at Start of Fluoride Administration

Larsen, M.J.; Richards, A.; Fejerskov, $0 \quad 519$

Influence of Xylitol- and/or Fluoride-Containing Toothpastes on the Remineralization of

Surface Softened Enamel Defects in vivo

Smits, M.T.; Arends, J 528

Measurement of Human Plaque Acidity: Comparison of Interdental Touch and Indwelling

Electrodes

Harper, D.S.; Gray, R.; Lenke, J.W.; Hefferren, J.J 536

In vivo Plaque Formation on Enamel Surfaces Treated with Topical Fluoride Agents

Dijkman, A.G.; Nelson, D.G.A.; Jongebloed, W.L.; Weerkamp, A.H.; Arends, J. ... 547

Announcements

33rd Annual ORCA Congress 1986

558

ORCA-Rolex Prize, and Other Events

Acknowledgements

560

Author Index 562

Subject Index 565 